\title{
ANÁLISE DE RISCO EM TÚNEIS RODOVIÁRIOS. A SITUAÇÃO EM PORTUGAL FACE À DIRECTIVA 2004/54/CE
}

\begin{abstract}
Jorge Saraiva ${ }^{1}$
Rute Saraiva ${ }^{2}$

\section{RESUMO}

A transposição não completa da chamada Directiva dos Túneis (Directiva 2004/54/CE) para o enquadramento jurídico português (Decreto-Lei 75/2006 e posterior Decreto-Lei75/2014) leva a que não exista um procedimento nacional de Análise de Risco (AR) para aquelas infraestruturas. O único procedimento possível passaria por verificar alínea por alínea os anexos do Decreto-Lei (por sinal transcritos praticamente ipsisverbus dos da Directiva) o que se traduz numa quase inutilidade pois a verificação da resposta à grande maioria dos requisitos passa por um simples sim ou não. $O$ presente artigo procura resumidamente apresentar os aspectos e limitações legais apresentando ainda uma forma de enquadramento que permite uma assumpção de responsabilidades por parte dos projectistas e autoridades com jurisdição. São ainda apresentados uma metodologia e um método que permitem, seguindo a verificação requisito a requisito, quantificar o risco para um túnel por comparação desse risco com o que se verificaria se esse mesmo túnel cumprisse, exactamente, cada um dos requisitos. Um caso de aplicação para um túnel bireccional de comprimento da ordem de $9 \mathrm{~km}$ é apresentado permitindo ilustrar que o procedimento pode ser aplicado em países em que 0 cumprimento da Directiva não é obrigatório.
\end{abstract}

Palavras-chave: Análise de Risco; Túneis Rodoviários; Directiva 2004/54/CE-

DL 75/2016; Metodologia e Procedimentos

\footnotetext{
${ }^{1}$ Investigador Coordenador, Laboratório Nacional de Engenharia Civil (aposentado); Dinâmica Aplicada

${ }^{2}$ Professora, Faculdade de Direito da Universidade de Lisboa
} 


\title{
ROAD TUNNELS RISK ANALYIS. THE PORTUGUESE SITUATION ON THE TRANSPOSITION OF 2004/54/EC
}

\begin{abstract}
The Portuguese Decree-Law 75/2006 that transposes the European Directive 2004/54/EC on minimum safety requirements for tunnels in the Trans-European Road Network is not fully applicable as it does not accomplish with what is stated in no2 of article 13 (risk analysis, RA): "Member States shall ensure that, at national level, a detailed and well-defined methodology, corresponding to the best available practices, is used and shall inform the Commission of the methodology applied; ...". So being the only lawful way to perform a RA for Portuguese tunnels is to follow item by item the requirements defined in the Annexes both in the Directive and in the Decree-Law 75/2006. This procedure is quite limitative as for most of those requirements a statement like "it has been considered" is enough as the items are, in what concerns quantitative and technical definitions, vague. The paper presents the law frame and a methodology, together with the correspondent procedure, that can overcome the fault. Both methodology and procedure can be used by those producing RA for road tunnels in countries where the Directive does not apply. An example of application for a bidirectional tunnel $9 \mathrm{~km}$ long is presented to illustrate the methodology and the procedure potential.
\end{abstract}

Keywords: Risk Analysis; Road Tunnels; Directive 2004/54/EC and DecreeLaw 75/2006; Methodology and Procedures.

\section{INTRODUÇÃO}

A Directiva 2004/54/CE (de 27 de Abril) relativa aos requisitos mínimos de segurança para os túneis da Rede Rodoviária Transeuropeia estabelece no 
o 2 do seu artigo 13ำ - Análises de Risco - Os Estados-Membros devem garantir a utilização, a nível nacional, de uma metodologia detalhada e bem definida, que corresponda às melhores práticas disponíveis, e devem informar a Comissão da metodologia aplicada;

O Estado Português na transposição para o quadro legislativo nacional (Decreto-Lei 75/2006), e nas posteriores alterações, Decreto-Lei 75/2014 (de 13 de Maio), nunca cumpriu esta exigência pelo que pode afirmar-se que a Análise de Risco é um exercício que depende de quem o constrói, interpreta e concretiza.

De facto, do ponto de vista legal a situação é clara já que a Lei 31/2009 (de 3 de Julho), que estabelece o regime de qualificação profissional dos responsáveis por projectos, exige destes uma declaração de responsabilidade que constitui garantia bastante do cumprimento das normas legais e regulamentares aplicáveis, permitindo-lhes mesmo declarar quais as normas técnicas ou regulamentares em vigor que não foram observadas na elaboração dos mesmos, fundamentando as razões da sua não observância. Isto significa que podem declarar que não procederam à Análise de Risco por esta não ter sido "Regulamentada". Isto também significa que nenhuma entidade, nomeadamente as definidas naquele Decreto-Lei, pode exigir mais que a verificação dos requisitos mínimos nos estritos termos em que ali figuram.

Já do ponto de vista técnico, a questão pode ser mais complexa pois a forma como os requisitos estão definidos é tão vaga que a sua verificação não impõe, na quase totalidade dos casos, mais do que um simples sim ou não.

Assim, procurando suprir a lacuna Regulamentar, apresenta-se na presente comunicação uma metodologia e um procedimento associado que sejam suportados no enquadramento legal. 


\section{QUESTÕES JURÍDICO-TÉCNICAS NA TRANSPOSIÇÃO DA DIRECTIVA 2004/54/CE}

A Directiva 2004/54/CE, sobre os requisitos mínimos de segurança para túneis da Rede Rodoviária Transeuropeia (RRT), foi transposta dois anos mais tarde para o ordenamento jurídico nacional pelo Decreto-Lei 75/2006, com as alterações entretanto introduzidas pelos Decretos-Lei 308/2009 e 75/2014 que, numa óptica de optimização e maximização de eficiência num contexto de crise económica e financeira, procede a uma revisão do modelo Regulatório do sector rodoviário promovendo, de acordo com os considerandos deste último diploma, a "redução, de forma sustentável e sem pôr em causa os requisitos de segurança rodoviária, dos encargos públicos emergentes dos contratos celebrados pelo Estado no âmbito deste sector".

Complementarmente, este último DL introduz uma distinção entre os túneis da RRT e os túneis da Rede Rodoviária Nacional (RRN) ao alargar até 31 de Dezembro de 2020 o prazo de renovação destes. Ora, esta obrigação, para estruturas já projectadas, concluídas e em serviço, parece, em especial num contexto de contenção de custos (mesmo se diluídos no tempo), manifestamente desproporcional, indo de encontro, aliás, àquilo que é jurídica e tradicionalmente aceite em matéria de exigências técnicas na construção. Afinal, estes túneis cumprem (ou pelo menos deviam cumprir) a legislação da época em que foram projectados e/ou edificados. Com efeito, a retroactividade das novas imposições técnicas, mesmo se por questões de interesse público associadas à redução do risco e perigosidade, deve ser ponderada tendo em atenção direitos entretanto constituídos e os custos da intervenção face aos seus benefícios, considerando as probabilidades e magnitude dos potenciais danos.

Neste sentido o legislador nacional, no Decreto-Lei 555/99 (RJUE, de 16 de Dezembro), apesar das duas dezenas de alterações que já promoveu no articulado, manteve inalterado o $n^{\circ} 1$ do art $^{-0}$ 60. que estabelece o princípio 
geral da irretroactividade, isto é, às construções levadas a cabo ao abrigo de legislação anterior (e as respectivas utilizações) não se aplica o Direito superveniente. No limite, apenas se aceita, numa combinação dos no 2 a 4 daquela disposição, a imposição de condições específicas à realização dos trabalhos acessórios que se mostrem necessários para a melhoria das condições de segurança (e salubridade) no caso de obras de reconstrução ou de alteração (sujeitas a comunicação prévia). Ou seja, não existindo estas (por iniciativa de quem de Direito) não se impõe a recuperação do existente nos termos do enquadramento jurídico e regulamentar, mesmo em termos de acréscimo de segurança. O mesmo pode ser verificado a propósito da segurança sísmica ou de incêndios.

Em suma, no plano nacional, o respeito pelo princípio da irretroactividade do Direito superveniente ser aplicado a estruturas já construídas, não obrigando, por via de regra, a reabilitações compulsórias à luz das novas exigências, aliado ao princípio da proporcionalidade, numa lógica de não onerar excessiva, desadequada e desnecessariamente quem detém direitos de apropriação sobre o regularmente construído, sugere o carácter despropositado da submissão dos túneis da RRN, não incluídos na RRT, ao regime superveniente e mais apertado desta (até pelas características físicas das suas infra-estruturas). A isto acresce, como se iniciou por referir, a própria ratio de eficiência subjacente à aprovação do Decreto-Lei n.. $75 / 2014$, manifestada no seu preâmbulo.

Uma segunda questão relativa à transposição da Directiva prende-se com o seu art ${ }^{0} 13.0$ que prevê, no no 1 , a elaboração de análises de risco casuísticas e no n.․ 2 o dever dos Estados-Membros estabelecerem e aplicarem, a nível nacional, uma "metodologia detalhada e bem definida, que corresponda às melhores práticas disponíveis", a ser comunicada à Comissão para que a partilhe com os outros Estados-Membros, a avalie e possa até propor uma metodologia comum harmonizada. 
Constata-se que nem o art ${ }^{\circ}$ 20. do Decreto-Lei 75/2006 (ou do DecretoLei 75/2014), referente a análise de riscos, nem nenhuma outra disposição do(s) mesmo(s) ou de outro(s) diploma(s) definem a metodologia nacional. $O$ art ${ }^{\circ}$ 20. mais não é do que uma cópia muito fiel, com alterações meramente de estilo e de forma, do n.. 1 do artigo 13.. da Directiva. Daqui decorre que, 15 anos volvidos sobre a publicação do acto legislativo europeu, Portugal continua em incumprimento sem o estabelecimento (e consequente aplicação) de uma metodologia de Análise de Risco própria, o que, inevitavelmente, tem implicações práticas para além do seu sancionamento por conduta inadimplente.

Com efeito, e em última instância, isto significa que o país carece totalmente da exigida quantificação e mesmo da qualificação do risco em túneis rodoviários (RRT e RRN), pelo que, face a esta lacuna, na ausência de uma metodologia europeia harmonizada, a análise de risco acaba por depender de quem a constrói, interpreta e concretiza. Do ponto de vista técnico (que não jurídico) pode pôr-se a questão de existirem recomendações que permitam a quem desenvolve este tipo de análises, de um lado, cumprir a exigência legislativa e, de outro, seguir alguns procedimentos que tornem a sua aplicação um verdadeiro instrumento de avaliação do risco. Mas, no final, a responsabilidade recai sobre o autor do projecto.

Efectivamente, do regime geral, leia-se dos art ${ }^{\circ} 10 .$. e $20 . \circ$ n. .9 do RJUE mas também do arto 21.- n. 3 da Lei 31/2009 (com as alterações introduzidas pelas Leis n.os 40/2015, de 1 de Junho, e 25/2018, de 14 de Junho), que estabelece o regime de qualificação profissional dos responsáveis por projectos e pela fiscalização e direcção de obra, decorre que os termos de responsabilidade dos projectistas constituem garantia bastante do cumprimento das normas legais e regulamentares aplicáveis, posto que nestes se declara e atesta que foram observadas, na elaboração das edificações e estruturas, as normas legais e regulamentares aplicáveis, mormente as normas técnicas em vigor, dando cumprimento aos seus deveres próprios. Ademais, o n. -5 do art $^{-}$ 
$10 .^{\circ}$ acrescenta que os projectistas "devem declarar (...) quais as normas técnicas ou regulamentares em vigor que não foram observadas na elaboração dos mesmos, fundamentando as razões da sua não observância."

Assim se entende a obrigação de celebração de contrato de seguro de responsabilidade civil extracontratual por parte destes (e de outros) agentes. Mais, do exposto resulta que nenhuma entidade, incluindo a Autoridade Administrativa, tem o poder de impor ou limitar qualquer Análise de Risco apresentada e respectivas consequências, desde que se respeite $o$ articulado

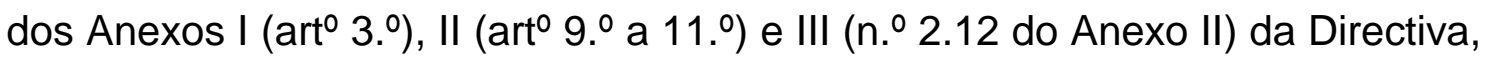
transpostos literalmente para a legislação nacional. Naturalmente, a adopção deste princípio tem implicações a nível da segurança da circulação em túneis e a responsabilidade final do projectista, por um lado, pode inibi-lo a subscrever 0 projecto e, por outro, caso "arrisque", a rejeitar interferências, mormente de quem não responderá por ele.

Para além de outras questões que se poderiam analisar no âmbito da legislação em vigor há uma última questão particularmente importante a ser considerada no âmbito da metodologia que se propõe: o princípio da "compensação" de "requisitos mínimos". A Directiva e a legislação nacional de transposição determinam que os únicos requisitos que não admitem desvios são os cinco referentes aos utentes, no ponto 1.2.2 do Anexo I, se bem que se aceite para túneis existentes alguma relaxação, desde que seja devidamente compensada por outras medidas (pontos 2.3.7; 2.5.2; e 2.10.3 do Anexo I), da mesma forma que no ponto 1.2.12 do Anexo I se concedem desvios limitados quanto a requisitos mínimos, desde que se estipulem e avaliem medidas alternativas de redução de riscos (que podem incluir as referentes a qualquer dos requisitos mínimos; é, por exemplo, corrente na quase totalidade dos países da UE considerar a redução da distância entre saídas para evacuação pedonal) para garantir, pelo menos, um nível de segurança equivalente. Em suma, sobretudo ponderando os considerandos da Directiva não transpostos para um proémio ou disposição normativa no plano nacional, tais como os 
considerandos 6, 13, 18 e 19, o que está em causa é assegurar a proporcionalidade na sua tripla vertente de adequação, necessidade e não excesso, pelo que, se a isto se somar a lógica de eficiência (financeira), prevista, como supra mencionado, no preâmbulo do Decreto-Lei n. $-75 / 2014$, se deve permitir, em Portugal, a possibilidade de recurso a medidas alternativas de compensação de requisitos mínimos que se revelem casuisticamente desproporcionados ou ineficientes.

\section{METODOLOGIA DE ANÁLISE DE RISCO}

A metodologia de AR que se propõe na presente comunicação segue o seguinte procedimento: analisar sequencialmente todos os itens e estabelecer um duplo balanço: o primeiro, levado a cabo dentro de cada grupo, consiste em verificar se os requisitos específicos do grupo podem, no mínimo, cancelar-se entre si; o segundo é levado a cabo de forma semelhante, mas entre os diferentes grupos.

Deve ser referido que os balanços podem apresentar dois aspectos: qualitativo e quantitativo, sendo que ambos podem ser usados ao mesmo tempo já que na maior parte (se não na totalidade) dos casos a aplicação qualitativa toma a forma de uma inequação, isto é, maior ou menor ( $>$ ou $<$ ) que um certo valor, conforme resulta da metodologia geral que consiste em atribuir um valor numérico para pesar cada item seguindo o procedimento seguinte:

1 - Um valor unitário (1) é atribuído aos itens a que os requisitos mínimos não são aplicáveis ou, em que sendo aplicáveis, cumprem exatamente a exigência Regulamentar; isto significa que estes requisitos são neutros quando se consideram no cômputo global da segurança/risco da infraestrutura;

2 - Valores (pesos) diferentes da unidade são atribuídos aos requisitos que vão além, ou ficam aquém, das exigências mínimas regulamentares: valores acima da unidade traduzem o nível de excedência daqueles requisitos 
mínimos e, correspondentemente, valores inferiores à unidade traduzem o nível de falha. Vale referir que valores inferiores à unidade são o inverso de números superiores a este valor, donde resulta que a mesma ordem de precisão pode ser obtida para os pesos, não sendo particularmente relevante considerar se são superiores ou inferiores ao valor de referência;

3 - Alguns valores podem ser mantidos como qualitativos na medida em que podem ser definidos como superiores ou inferiores a um determinado valor.

É importante deixar claro que estes pesos se aplicam, excepto (para os novos túneis) a 5 (cinco) dos requisitos mínimos, como especificamente exigido pela Directiva no §1.2.2 do Anexo I. Para estes 5 requisitos - todos referentes ao chamado "pilar utentes" - o peso não pode ser inferior à unidade. Não menos importante é chamar a atenção para o facto de alguns destes requisitos não serem obrigatórios para os túneis existentes (basicamente são relaxadas as exigências), se bem que, nesse caso, possa ser necessário considerar medidas compensatórias (caso, por exemplo, das saídas de emergência ou das distâncias entre postos de socorro sucessivos).

A forma de estabelecer os pesos é suportada no trabalho de diferentes Instituições, nomeadamente PIARC, CETU, TNO, SPF, ...; em Regulamentação e Normas devidamente adaptadas, como é o caso do RABT (Alemanha), RVS (Áustria), Circulaires (França) ou ASTRA (Suíça), ...; em diferentes estudos específicos levados a cabo ao longo dos últimos anos por grupos de trabalho multinacionais que desenvolveram projectos na área da Segurança de Túneis, como o FIT, UPTUNNEL ou SAFET, ...; sendo, no entanto, por uma questão de simplificação considerados, sempre que possível, modelos lineares (razoáveis em quase todos os casos, em especial se os desvios em relação aos parâmetros em análise forem pequenos).

Uma vez estimados os pesos, o balanço para cada grupo é estabelecido pelo produto directo de todos os pesos integrados no mesmo grupo. Este 
procedimento é suportado nos princípios jurídicos de aplicação das leis. De facto, se a lei não define diferentes condições de aplicação para diferentes cláusulas dentro de um determinado campo de aplicação, as cláusulas devem ser interpretadas como igualmente relevantes.

Note-se que existe uma condição que decorre de a Directiva: admitir medidas compensatórias, nomeadamente as que decorrem de margens de segurança que possam existir na forma como cada um dos requisitos é especificamente aplicado (exceptuam-se deste regime os cinco requisitos já atrás especificados). A prova que (re)confirma esta interpretação decorre do texto do §1.1.3 pois, se assim não fosse, o texto regulamentar (se são necessárias medidas de segurança adicionais e/ou equipamentos suplementares) não seria condicional.

O passo seguinte consiste em aplicar o mesmo procedimento (produto) a todos os grupos e verificar se a compensação interna ocorre sem recurso a medidas de segurança adicionais e/ou equipamentos suplementares.

A primeira parte do procedimento considera apenas a infraestrutura e, como tal, torna-se necessário pesar os requisitos adicionais, nomeadamente os expressos nos $\S 3.1$ a $\$ 3.9$. Nos procedimentos ligados à operação, o resultado final deve ser combinado com os que têm origem na $A R$ associada à infraestrutura, de forma a verificar, mais uma vez, se uma compensação pode ser conseguida sem recurso a medidas de segurança adicionais e/ou equipamentos suplementares. Ambos os conjuntos de requisitos mínimos estão relacionados (algumas das medidas consideradas na infraestrutura visam obviamente suportar exigências de funcionamento) e não há dúvida que ambas devem ser satisfeitas ao mesmo tempo.

$\mathrm{Na}$ realidade a Directiva vai mais longe que isso ao considerar, em simultâneo e como igualmente importantes, a integração dos 4 pilares que permitem garantir os elevados níveis de segurança na utilização dos túneis 
rodoviários, como se pode constatar pelo expresso no §1.1.1 do Anexo I, que se vem referindo: "As medidas de segurança a aplicar num túnel devem assentar numa ponderação sistémica de todos os aspectos do sistema composto pela infraestrutura, o funcionamento, os utentes e os veículos".

Utentes e Veículos, os dois outros pilares, não são incluídos no âmbito deste tipo de AR, a não ser, para o caso dos Utentes, os 5 itens já referidos (túneis novos) e, no caso dos Veículos, os valores das emissões associadas ao parque nacional (se bem que cumprindo a regulamentação da UE sobre emissões) e as obrigações que decorrem (neste ponto específico: veículos) da mais recente edição da Directiva de circulação de mercadorias perigosas (dita Directiva $A D T$ ) e da sua transposição para a ordem jurídica portuguesa (Decreto-Lei 111_A/2017 (de 31 de Agosto)) que contém igualmente exigências que vão afectar as condições de circulação, não apenas dos túneis mas de toda a rede rodoviária.

\section{CASO DE APLICAÇÃO}

Um dos túneis a que se aplicou a metodologia é um caso particularmente rico já que é um túnel integrado numa auto-estrada.

Com uma TMDA esperada de 9000 veículos, dos quais, dependendo da estação do ano, 40 a $60 \%$ são transporte de mercadorias (algumas das quais classificadas como perigosas), foi decidido (custo/benefício) construí-lo como bidirecional. A galeria tem $9000 \mathrm{~m}$ de comprimento. O perfil vertical é um $\mathrm{V}$ invertido com o ponto mais elevado localizado a meio do túnel, sendo o gradiente dos dois troços de $\sim 1 \%$ para um dos lados e da ordem de $0,5 \%$ para o outro. O alinhamento horizontal é praticamente uma linha recta, à excepção do troço próximo do portal de maior cota, onde o eixo descreve uma espécie de $S$ muito alongado. 
A secção recta típica está representada na figura 1 e conforme pode ser verificado o sistema de ventilação é transversal (2 condutas que correm sobre a galeria rodoviária), sendo o escoamento longitudinal controlado por ventiladores de impulso.

A figura 2, por seu lado, mostra de forma esquemática a galeria principal bem como o túnel de evacuação que corre paralelo a este. Existem galerias de evacuação pedonais, semáforos e painéis de sinais variáveis (todos os $300 \mathrm{~m}$ ) bem como galerias dos serviços de emergência (todos os $1200 \mathrm{~m}$ ). Há nichos de postos SOS associados a equipamento de combate a incêndios, incluindo os hidrantes de uma linha de água (todos os $150 \mathrm{~m}$ ). Existe um sistema de CCTV (câmaras todos os $75 \mathrm{~m}$ ) e outros equipamentos entre os quais detectores de $\mathrm{CO}$ e visibilidade, bem como anemómetros (todos os $600 \mathrm{~m}$ ), e ainda um detector linear de calor.

As duas tabelas seguintes (apresentadas em inglês, uma vez que são directamente transpostas do documento submetido às autoridades com jurisdição no país em que se situa o túnel e por elas aprovado) ilustram a aplicação. 


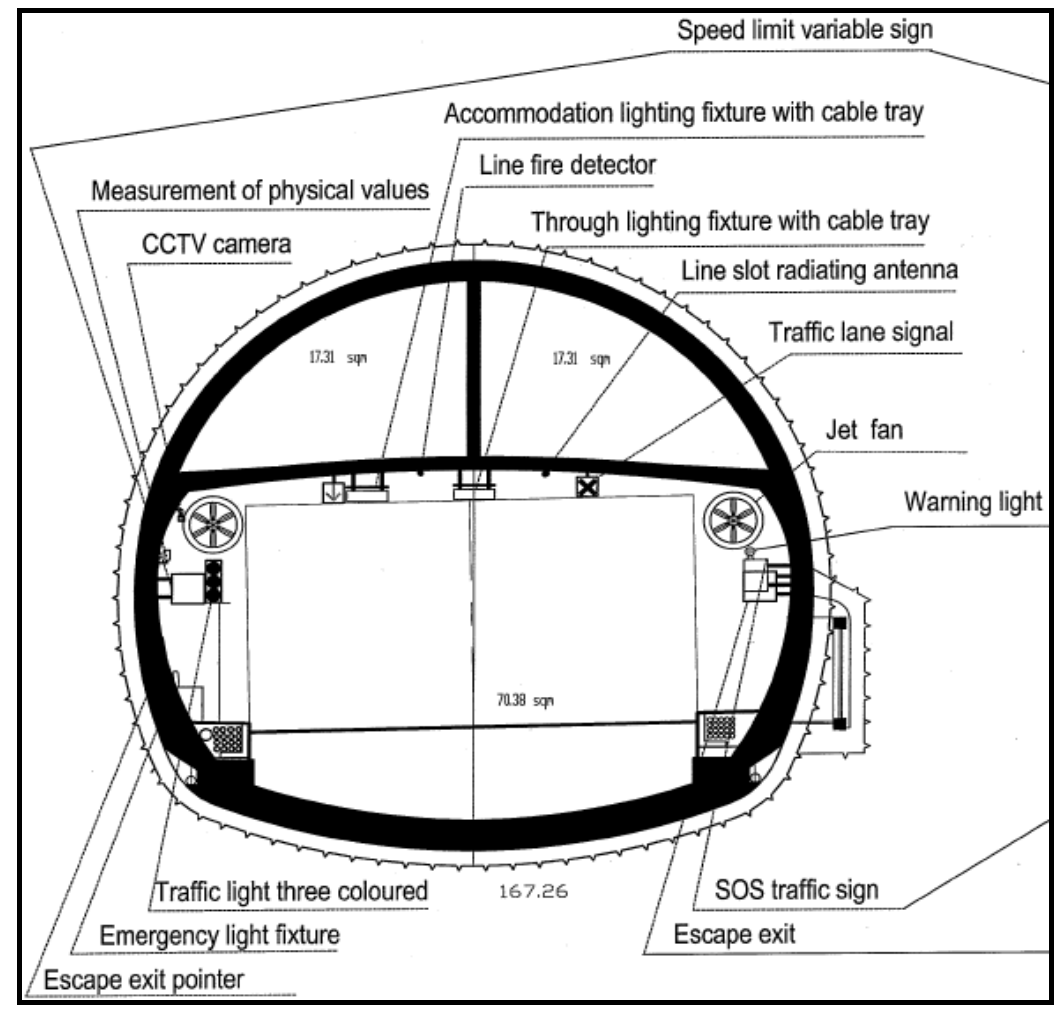

Figura 1 - Secção recta do túnel

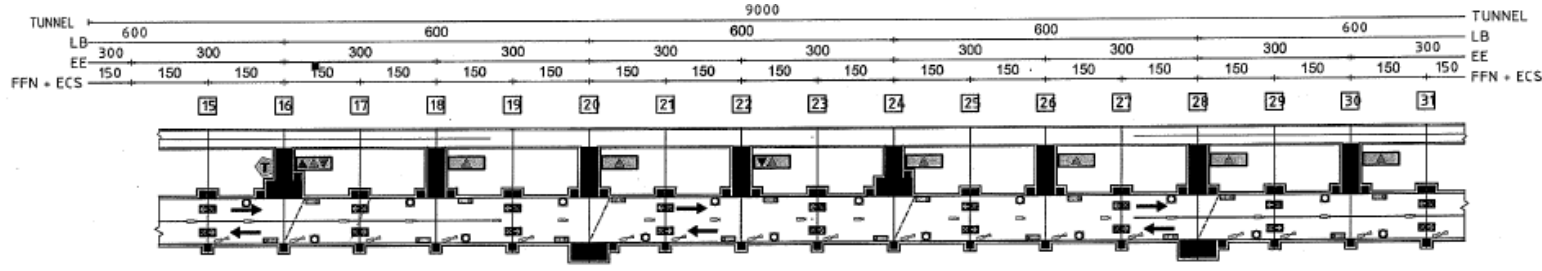

Figura 2 - Sector intermédio do túnel (galerias principal e de emergência e equipamentos)

A primeira é uma óbvia adaptação da tabela resumo que figura tanto na Directiva como no Decreto-Lei. Poderia dizer-se que é a tabela que define os requisitos mínimos para a infraestrutura. Nela destacam-se duas colunas: uma onde estão expressos os pesos (Weight) e outra onde figura a existência de condições adicionais e comentários (Additional .... or comments). A segunda tabela procura resumir os requisitos operacionais. 
Vol. 05 N.14 - Edição Especial 5 CILASCI -- ISSN 2359-4829

Versão on-line disponível em: http://www.revistaflammae.com

Tabela 1 - Sumário dos Requisitos Mínimos para a Infraestrutura

\begin{tabular}{|c|c|c|c|c|c|}
\hline \multirow{2}{*}{\multicolumn{2}{|c|}{$\begin{array}{l}\text { Summary of mínimum } \\
\text { requirements }\end{array}$}} & \multirow{2}{*}{\multicolumn{2}{|c|}{$\begin{array}{l}\text { Traffic }>2000 \\
\text { per lane } \\
L>3000 \mathrm{~m}\end{array}$}} & \multirow{3}{*}{$\begin{array}{l}\text { Weigh } \\
\mathbf{t} \\
\sim 2\end{array}$} & \multirow{3}{*}{$\begin{array}{l}\begin{array}{l}\text { Additional conditions for } \\
\text { implementation to } \\
\text { mandatory, or comments }\end{array} \\
\begin{array}{l}\text { ADT }(2030) 4500 \text { veh/lane } \\
\text { (ref. ADT 10000) }^{(1)}\end{array} \\
\end{array}$} \\
\hline & & & & & \\
\hline \multirow{9}{*}{$\begin{array}{l}\text { Structur } \\
\text { al } \\
\text { measur } \\
\text { es }\end{array}$} & 2 tubes or more & $\S 2.1$ & & & \\
\hline & Gradients $<5 \%$ & $\S 2.2$ & * & 1 & $\begin{array}{l}\text { Gradients } 0.5 \text { and } 1 \% \text { (ref. } 3 \% \text { ) } \\
\text { According with directive }\end{array}$ \\
\hline & Emergency walkways & $\begin{array}{l}\S 2.3 .1 \\
\S 2.3 .2\end{array}$ & * & $>1$ & $\begin{array}{l}1 \text { elevated walkway and } 1 \\
\text { shoulder lane each side }(1,2 \mathrm{~m}) \\
\text { Above directive requirements }{ }^{(2)}\end{array}$ \\
\hline & $\begin{array}{l}\text { Emergency exits at } \\
\text { least every } 500 \mathrm{~m}\end{array}$ & $\begin{array}{l}\text { §2.3.3 } \\
\text { to } \\
\S 2.3 .9\end{array}$ & * & $\begin{array}{l}1,2 \\
\text { to } \\
1,5\end{array}$ & $\begin{array}{l}300 \mathrm{~m} \text { Above directive } \\
\text { requirements (ref. } 500 \mathrm{~m}) \text {. } \\
\text { Linear Evac model }^{(3)}\end{array}$ \\
\hline & $\begin{array}{l}\text { Cross connections for } \\
\text { emergency services at } \\
\text { least every } 1500 \mathrm{~m}\end{array}$ & $\S 2.4 .1$ & • & 1,2 & $\begin{array}{l}1200 \mathrm{~m} \text { Above directive } \\
\text { requirements (ref. } 1500 \mathrm{~m})^{(3)}\end{array}$ \\
\hline & $\begin{array}{l}\text { Crossing of the central } \\
\text { reserve outside each } \\
\text { portal }\end{array}$ & $\S 2.4 .2$ & $\bullet$ & 1 & According with directive \\
\hline & $\begin{array}{l}\text { Lay-bys at least every } \\
1000 \mathrm{~m}\end{array}$ & $\S 2.5$ & o/• & $>1$ & $\begin{array}{l}600 \mathrm{~m} \text { Above directive } \\
\text { requirements (ref. } 1000 \mathrm{~m} \text { ) }\end{array}$ \\
\hline & $\begin{array}{l}\text { Drainage forflammable } \\
\text { and toxic liquids }\end{array}$ & $\S 2.6$ & * & 1 & According with directive \\
\hline & $\begin{array}{l}\text { Fire resistance of } \\
\text { structures }\end{array}$ & $\S 2.7$ & • & 1 & According with directive \\
\hline \multicolumn{4}{|c|}{ Balance for structural measures } & $>3$ & $\begin{array}{l}\text { Above directive requirements } \\
\text { (operational requirements } \\
\text { demand compensation) }\end{array}$ \\
\hline \multirow{3}{*}{ Lighting } & Normal & $\S 2.8 .1$ & $\cdot$ & 1 & According with directive \\
\hline & safety & $\S 2.8 .2$ & - & 1 & According with directive \\
\hline & evacuation & $\S 2.8 .3$ & $\cdot$ & 1 & According with directive \\
\hline \multicolumn{4}{|c|}{ Balance for lighting } & 1 & Comply with directive \\
\hline \multirow{2}{*}{$\begin{array}{l}\text { Ventilati } \\
\text { on }\end{array}$} & Mechanical Ventilation & $\S 2.9$ & • & $>2$ & $\begin{array}{l}100 \% \text { redundant system. } \\
\text { Above directive requirements } \\
\text { (design fire } 30 \mathrm{MW}-\text { capability } \\
\text { of the system above } 50 \mathrm{MW} \text { ) }\end{array}$ \\
\hline & $\begin{array}{l}\text { Special provisions for } \\
\text { (semi-transverse } \\
\text { ventilation }\end{array}$ & $\S 2.9 .5$ & • & 1 & According with directive \\
\hline \multicolumn{4}{|c|}{ Balance of Ventilation } & $>2$ & Above directive requirements \\
\hline
\end{tabular}


Revista FLAMMAE

Revista Científica do Corpo de Bombeiros Militar de Pernambuco

Vol. 05 N.14 - Edição Especial 5 CILASCI -- ISSN 2359-4829

Versão on-line disponível em: http://www.revistaflammae.com

\begin{tabular}{|c|c|c|c|c|c|}
\hline \multirow{2}{*}{\multicolumn{2}{|c|}{$\begin{array}{l}\text { Summary of mínimum } \\
\text { requirements }\end{array}$}} & \multirow{2}{*}{\multicolumn{2}{|c|}{$\begin{array}{l}\text { Traffic }>2000 \\
\text { per lane } \\
\mathrm{L}>3000 \mathrm{~m} \\
\end{array}$}} & \multirow{3}{*}{$\begin{array}{l}\text { Weigh } \\
\mathbf{t} \\
1\end{array}$} & \multirow{3}{*}{$\begin{array}{l}\text { Additional conditions for } \\
\text { implementation to } \\
\text { mandatory, or comments }\end{array}$} \\
\hline & & & & & \\
\hline $\begin{array}{l}\text { Emerge } \\
\text { ncy } \\
\text { stations }\end{array}$ & At least every $150 \mathrm{~m}$ & $\S 2.10$ & * & & \\
\hline \multicolumn{4}{|c|}{ Balance of emergency stations } & 1 & Comply with directive \\
\hline $\begin{array}{l}\text { Water } \\
\text { supply }\end{array}$ & At least $250 \mathrm{~m}$ & $\S 2.11$ & • & 1 & According with directive \\
\hline \multicolumn{4}{|c|}{ Balance of wáter supply } & 1 & Comply with directive \\
\hline $\begin{array}{l}\text { Road } \\
\text { signs }\end{array}$ & & $\S 2.12$ & • & $>1$ & $\begin{array}{l}\text { Every } 300 \mathrm{~m} \\
\text { Above directive requirements }\end{array}$ \\
\hline \multicolumn{4}{|c|}{ Balance of road signs } & $>1$ & Above Directive requirements \\
\hline $\begin{array}{l}\text { Control } \\
\text { centre }\end{array}$ & & $\S 2.13$ & - & 2 & $\begin{array}{l}\text { Two control centers (one as a } \\
\text { full reserve in case of failure) })^{(5)} \\
\text { Above directive requirements }\end{array}$ \\
\hline \multicolumn{4}{|c|}{ Balance of control centre } & 2 & Above directive requirements \\
\hline \multirow{2}{*}{$\begin{array}{l}\text { Monitori } \\
\text { ng } \\
\text { systems }\end{array}$} & Video (CCTV) & $\S 2.14$ & • & $>1$ & $\begin{array}{l}\text { DIA including smoke } \\
\text { Above directive requirements }\end{array}$ \\
\hline & $\begin{array}{l}\text { Automaticincidentdete } \\
\text { ction } \\
\text { and/orfiredetection }\end{array}$ & $\S 2.14$ & - & $>2$ & $\begin{array}{l}\text { Above directive requirements } \\
\text { LHD ( } 3 \text { modes), CCTV (DIA } \\
\text { and smoke) CO and oppacity } \\
\text { detection }^{(6)}\end{array}$ \\
\hline \multicolumn{4}{|c|}{ Balance of monitoring systems } & $>2$ & Above directive requirements \\
\hline \multirow{2}{*}{$\begin{array}{l}\text { Equipm } \\
\text { ent to } \\
\text { close } \\
\text { The } \\
\text { tunnel }\end{array}$} & $\begin{array}{l}\text { Traffic signals before } \\
\text { entrances }\end{array}$ & $\begin{array}{l}\$ 2.15 . \\
1\end{array}$ & • & $>1$ & Above directive requirements ${ }^{(7)}$ \\
\hline & $\begin{array}{l}\text { Traffic signals inside } \\
\text { the tunnel at least } \\
\text { every } 1000 \mathrm{~m}\end{array}$ & $\begin{array}{l}\S 2.15 . \\
2\end{array}$ & $@$ & $>1$ & $\begin{array}{l}\text { Every } 300 \mathrm{~m} \\
\text { Above directive requirements }{ }^{(7)}\end{array}$ \\
\hline \multicolumn{4}{|c|}{ Balance of equipments to close the tunnel } & $>1$ & Above directive requirements \\
\hline \multirow{3}{*}{$\begin{array}{l}\text { Commu } \\
\text { nication } \\
\text { systems }\end{array}$} & $\begin{array}{l}\text { Radio re-broadcasting } \\
\text { for } \quad \text { emergency } \\
\text { services }\end{array}$ & $\begin{array}{l}\S 2.16 . \\
1\end{array}$ & • & 1 & According with directive \\
\hline & $\begin{array}{l}\text { Emergency radio } \\
\text { messages for tunnels } \\
\text { users }\end{array}$ & $\begin{array}{l}\S 2.16 . \\
2\end{array}$ & • & 1 & According with directive \\
\hline & $\begin{array}{l}\text { Loudspeakers in } \\
\text { shelters and exits }\end{array}$ & §2.16. & • & 1 & According with directive \\
\hline \multicolumn{4}{|c|}{ Balance of communication systems } & 1 & Comply with directive \\
\hline
\end{tabular}


Revista FLAMMAE

Revista Científica do Corpo de Bombeiros Militar de Pernambuco

Vol. 05 N.14 - Edição Especial 5 CILASCI -- ISSN 2359-4829

Versão on-line disponível em: http://www.revistaflammae.com

\begin{tabular}{|c|c|c|c|c|}
\hline \multirow{3}{*}{$\begin{array}{l}\begin{array}{l}\text { Summary of mínimum } \\
\text { requirements }\end{array} \\
\text { Emergency power supply }\end{array}$} & \multirow{2}{*}{\multicolumn{2}{|c|}{$\begin{array}{l}\text { Traffic }>2000 \\
\text { per lane } \\
\mathrm{L}>3000 \mathrm{~m}\end{array}$}} & \multirow{3}{*}{$\begin{array}{l}\text { Weigh } \\
t \\
1\end{array}$} & \multirow{3}{*}{$\begin{array}{l}\text { Additional conditions for } \\
\text { implementation to be } \\
\text { mandatory, or comments }\end{array}$} \\
\hline & & & & \\
\hline & $\S 2.17$ & • & & \\
\hline \multicolumn{3}{|c|}{ Balance of emergency power supply } & 1 & Comply with directive \\
\hline Fire resistance of equipments & $\S 2.18$ & • & 1 & According with directive \\
\hline \multicolumn{3}{|c|}{ Balance of fire resistance of equipment } & 1 & Comply with directive \\
\hline
\end{tabular}

- Mandatory; *Mandatory with exceptions; o not mandatory; @ recommended

\begin{tabular}{|l|l|l|} 
RESULT (infrastructure) & $>24$ & $\begin{array}{l}\text { Strucutral measures, systems } \\
\text { and Equipments above } \\
\text { directive Requirements }\end{array}$
\end{tabular}

Tabela 2 - Sumário dos Requisitos Operacionais

\begin{tabular}{|c|c|c|c|c|}
\hline $\begin{array}{l}\text { Summary of minimum } \\
\text { requirements }\end{array}$ & \multicolumn{2}{|c|}{$\begin{array}{l}\text { Traffic }>2000 \\
\text { per lane } \\
L>3000 \mathrm{~m}\end{array}$} & $\begin{array}{l}\text { Weig } \\
\text { ht }\end{array}$ & $\begin{array}{ll}\text { Additional conditions } & \text { for } \\
\text { implementation to } & \text { be } \\
\text { mandatory, or comments } & \end{array}$ \\
\hline \multicolumn{5}{|l|}{ OPERATIONAL REQUIREMENTS } \\
\hline $\begin{array}{l}\text { Presence and percentage of } \\
\text { HGV }\end{array}$ & $\S 1.3 .2$ & $60 \%$ & $>0.25$ & $\sim 95 \%$ of $\mathrm{HGV}$ of 12 to $15 \operatorname{ton}^{(9)}$ \\
\hline Operating Means & $\S 3.1$ & & 1 & According with directive \\
\hline Emergency planning & $\S 3.2$ & & 1 & According with directive \\
\hline Works in tunnel & $\S 3.3$ & & 1 & According with directive \\
\hline Management of $\mathrm{I} / \mathrm{A}$ & $\S 3.4$ & & 1 & $\begin{array}{l}\text { According with directive } \\
\text { (emergency services at the } \\
\text { tunnel portals) }\end{array}$ \\
\hline Activity of the control centre & $\S 3.5$ & & 1 & According with directive \\
\hline Tunnel closure & $\S 3.6$ & & 1 & According with directive \\
\hline Transport of dangerous goods & $\S 3.7$ & & $>0.25$ & $\begin{array}{l}\text { Though above the directive no } \\
\text { ADT or vehicle inspection } \\
\text { mandatory (traffic control } \\
\text { includes outside overheight, } \\
\text { smoke emission and } \\
\text { temperatura of vehicle) }{ }^{(10)}\end{array}$ \\
\hline Overtaking & $\S 3.8$ & & 1 & $\begin{array}{l}\text { No overtake allowed } \\
\text { (just under operation control) }\end{array}$ \\
\hline $\begin{array}{l}\text { Distance between vehicles } \\
\text { and speed }\end{array}$ & $\S 3.9$ & & $>1$ & $\begin{array}{l}\text { Abovethe directive requirements } \\
\text { (in } 2030 \sim 1 / 2 \text { of tunnel traffic } \\
\text { capacity for peak hours used) }^{(11)}\end{array}$ \\
\hline Information campaigns & $\S 4$ & & 1 & According with directive \\
\hline RESULT (OPERATION) & & & $>0.06$ & $\begin{array}{l}\text { Operational conditions heavy } \\
\text { demanding compensation from } \\
\text { minimum requirements }\end{array}$ \\
\hline
\end{tabular}




\begin{tabular}{|l|l|l|}
\hline GLOBAL SAFETY COEFFICIENT & $\sim 1.5$ & $\begin{array}{l}\text { The probability of an accident } \\
\text { involving fatalities is about } 2 / 3 \\
\text { that to be expected for the } \\
\text { reference tunnel (directive) }\end{array}$ \\
\hline
\end{tabular}

Os índices superiores no fim do texto de última coluna indicam a posição numa lista numerada em conformidade que justifica o peso atribuído. Apenas a título ilustrativo apresentam-se algumas dessas justificações:

(1) O número de incidentes/acidentes é, em todas as estatísticas, proporcional ao no de veíc.km;

(3) Capacidade de evacuação todos os $300 \mathrm{~m}$ o que permite a comparação directa com a situação regulamentar pois os tempos de evacuação são proporcionais a uma constante com um termo linear associado à distância a percorrer;

(4) extracção massiva mínima de $200 \mathrm{~m}^{3} / \mathrm{s}$, em $200 \mathrm{~m}$, com controlo de velocidade longitudinal;

(7) a detecção é redundante: 5 sistemas e 7 procedimentos distintos;

(8) a alimentação eléctrica é feita em cada extremidade directamente a partir de subestações distintas; há uma ligação entre as alimentações dos transformadores;

\section{CONCLUSÕES}

A primeira conclusão é que é possível definir uma metodologia e construir um método de Análise de Risco suportado no articulado do DecretoLei 75/2006 (Anexos). Na realidade, são o conhecimento e a experiência de um projectista que podem ditar uma quantificação justificada (suportada no próprio 
desenvolvimento do projecto) o que significa que a AR pode ser desenvolvida em paralelo com o projecto.

Uma segunda conclusão é que análises quantitativas "clássicas" como as baseadas em metodologias FED (Fractional Effective Dose) ou em curvas F$\mathrm{N}$ (caso da metodologia DG-QRAM), ainda que aplicáveis teoricamente, exigem dados e estatísticas que não existem ou que não podem ser facilmente estimados.

A terceira conclusão é que a metodologia apresentada, como foi demonstrado pode ser (é) efectiva ao associar séries de procedimentos que permitem gerar um número (neste sentido é uma análise quantitativa) que representa uma margem de segurança quando comparado com o valor unitário a ser atribuído a um túnel de referência (todos os pesos unitários).

É importante notar que as medidas de compensação podem ser agrupadas em 4 categorias: estruturais; ventilação; centro de controlo; e monitorização. As primeiras são "estáticas" e o seu peso vem em grande parte do tráfego (TMDA), as outras são "dinâmicas", duas delas cruciais na detecção de incidentes/acidentes e a terceira (ventilação) na garantia de uma atmosfera viável.

\section{REFERÊNCIAS}

DIRECTIVA 2004/54/CE do Parlamento Europeu e do Conselho, de 29 de Abril de 2004, relativa aos requisitos mínimos de segurança para os túneis da Rede Rodoviária Transeuropeia, Jornal Oficial da UE L167 de 30 de Abril, Bruxelas

DECRETO-LEI 75/2006, Diário da República, Série I-A oㅜ 61 de 27de Março de 2006, Imprensa Nacional, Lisboa

DECRETO-LEI 75/2014, Diário da República, Série I-A no 91 de 13 de Maio de 2014, Imprensa Nacional, Lisboa 